\title{
, \\ Failure Modeling for QP980 Steel by a Shear Ductile Fracture Criterion
}

\author{
Songchen Wang ${ }^{1}$, Yue Wang ${ }^{1}$, Long $\mathrm{Yu}^{2}{ }^{2}$, Kang Ji ${ }^{2}$, Xiaochuan Liu ${ }^{1}$ and Yanshan Lou ${ }^{1, *(\mathbb{C})}$ \\ 1 School of Mechanical Engineering, Xi'an Jiao Tong University, 28 Xianning West Road, Xi'an 710049, China; \\ wangsc@stu.xjtu.edu.cn (S.W.); wy17796657548@stu.xjtu.edu.cn (Y.W.); liuxiaochuan2020@xjtu.edu.cn (X.L.) \\ 2 Beijing Institute of Astronautical Systems Engineering, Beijing 100076, China; 17718570617@189.cn (L.Y.); \\ jerryji1989@gmail.com (K.J.) \\ * Correspondence: ys.lou@xjtu.edu.cn
}

check for updates

Citation: Wang, S.; Wang, Y.; Yu, L.; Ji, K.; Liu, X.; Lou, Y. Failure Modeling for QP980 Steel by a Shear Ductile Fracture Criterion. Metals 2022, 12, 452. https://doi.org/10.3390/ met12030452

Academic Editors: Antonio Mateo and Irina P. Semenova

Received: 19 December 2021

Accepted: 3 March 2022

Published: 7 March 2022

Publisher's Note: MDPI stays neutral with regard to jurisdictional claims in published maps and institutional affiliations.

Copyright: (c) 2022 by the authors. Licensee MDPI, Basel, Switzerland. This article is an open access article distributed under the terms and conditions of the Creative Commons Attribution (CC BY) license (https:/ / creativecommons.org/licenses/by/ $4.0 /)$.

\begin{abstract}
The wide application of advanced high strength steels with high specific strength in the automotive industry can significantly reduce energy consumption and contribute to carbon neutrality. Accurate prediction of the ductile fracture behavior of advanced high strength steels under complex stress states is of great significance for its application in automobile industry. In this study, the ductile fracture behavior of QP980 under complex stress states, covering shear, uniaxial tension, and plane strain tension, is investigated by conducting the hybrid experiment and simulation. The pressurecoupled Drucker yield function is chosen to characterize the effect of stress states on yielding for QP980, considering its high accuracy compared with the von Mises yield function. Failure limit of the stress states is modelled by five uncoupled ductile fracture criteria (Brozzo, Oh, Rice-Tracey, Ko-Huh, and DF2012). To improve the numerical prediction accuracy, the parameters of the constitutive model are optimized by using the inverse engineering approach. The numerical predicted results are compared with the experimental load-stroke curves with the onset of fracture. The comparison indicates that the prediction error of the DF2012 criterion is significantly lower than those of the other four criteria. In addition, the prediction accuracy is greatly improved with the parameters of the constitutive model optimized by the inverse engineering.
\end{abstract}

Keywords: ductile fracture; advanced high strength steel; sheet metal forming; inverse engineering

\section{Introduction}

Energy conservation is crucial to the automotive industry, which can effectively reduce the costs of automobiles and greenhouse gas emissions to promote carbon-neutral. Research shows that approximately $75 \%$ of fuel consumption is positively correlated with the weight of automobile. A $10 \%$ reduction in weigh could contribute to $6-8 \%$ reduction in energy consumption and 13\% reduction in carbon dioxide emissions [1]. Therefore, the lightweight automobile can greatly reduce energy consumption. There are currently three main ways to achieve lightweight in the automotive industry, including topology optimization design, new lightweight materials, and new manufacturing technology. The application of new lightweight materials is beneficial to the weight loss of automobiles. Among them, QP980 of advanced high strength steel (AHSS) has high specific strength, not only reducing the weight but also increasing the safety of automobiles. The microstructure of QP980 at room temperature is a mixture of the martensite, ferrite, and retained austenite. The hard martensite improves the strength of QP980, while the soft ferrite enhances its ductility [2]. Consequently, QP980 is widely utilized in the automobile structures, such as B-pillar reinforcement plate. Nevertheless, ductile fracture is the main failure mode during the forming processes of AHSS. With the development of computer technology, the numerical simulation method can effectively predict the plastic deformation behavior of sheet metals in forming processes, thus avoiding the ductile fracture under wide loading conditions. 
Metals usually fail in virtue of the nucleation, growth, and coalescence of microscopic voids [3]. Many ductile fracture criteria have been proposed to predict the plastic deformation of sheet metals. Those ductile fracture criteria fall into two categories, namely coupled ductile fracture criteria considering the damage accumulation in constitutive model and uncoupled ones [4,5]. Bai and Wierzbicki [6] modified the Mohr-Coulomb criterion (MMC) and then successfully characterized the ductile fracture behavior of Al2024-T351 in a wide range of stress triaxiality. Zhang et al. [7] investigated the strain hardening behavior of AA5182-O aluminum alloy of under the stress states varying from shear to equibiaxial tension. Luo et al. [8] predicted the strain path changing effect on forming limits of AA 6111-T4 based on a shear ductile fracture criterion. Ghadikolaee et al. [9] studied the U-bending of AA6061-T6 aluminum alloy by using Ayada, Rice-Tracey, and normalized Cockroft-Latham fracture criteria. Chow and Jie [10] accurately predicted the forming limit of Al6022 aluminum alloy by using the Hill's quadratic anisotropic yield criterion based on the continuum damage mechanics. Luo and Wierzbicki [11] presented the failure of Dual Phase steel during stretch-bending operations by using the modified MMC. Xu et al. [12] proposed a new ductile criterion based on two typical fracture mechanisms, tension fracture and shear fracture, to predict the ductile fractures with stress triaxiality less than -1/3 for Al 6061-T6 and Al 2024-T351. Lou et al. [13,14] proposed ductile fracture criteria based on micromechanisms of ductile fracture: strain-controlled void nucleation, triaxiality-governed void growth, and shear coalescence of voids. Lou and Yoon [15] extended a stress-invariant-based function to model fracture limits of sheet metals. $\mathrm{Mu}$ et al. [16] developed a mathematical model of ductile fracture behavior by considering two major void deformation modes and calibrated the model for DP780 using a hybrid experimental-numerical method. On the one hand, all the above research are to investigate the ductile fracture behavior of sheet metals under different stress triaxiality, which can accurately characterize the deformation behavior of sheet metal under complex stress state. On the other hand, a single ductile fracture criterion is mainly used to simulate the ductile fracture behavior of sheet metals. Therefore, various ductile fracture criteria were used to characterize the ductile fracture behavior of QP980 under complex stress states.

In this paper, the plastic deformation behavior of QP980 sheet metal under various stress states of shear (in-plane shear specimen), uniaxial tension (specimen with a central hole), and plane strain tension (notched specimen) was investigated by conducting experiments and simulations. The material strength was subsequently predicted by using the von-Mises and pressure-coupled Drucker yield criteria. On this basis, four traditional uncoupled ductile fracture criteria and DF2012 criterion were used to simulate the ductile fracture of QP980. In addition, the parameters of the constitutive models and ductile fracture criteria were optimized by using an inverse engineering approach to improve the prediction accuracy.

\section{Experiments}

\subsection{Material}

QP980 with the thickness of $1.0 \mathrm{~mm}$ was used to evaluate the ductile fracture under complex stress state during forming processes, and its chemical compositions are shown in Table 1. Four types of specimens shown in Figure 1 were fabricated to investigate the deformation behavior under uniaxial tension, plane strain tension, and shear stress states. The dog-bone specimen is used to characterize plastic behavior under uniaxial tension. The specimen with a central hole characterizes fracture at uniaxial tension, the notched specimen for fracture at plane strain tension, and the in-plane shear specimen for fracture at shear. It should be pointed out that prior fracture would occur at circular edge for the notched specimen. Accordingly, a parallel groove with $3 \mathrm{~mm}$ was embedded for the notched specimens to avoid stress concentration and ensure the fracture initiating from the notched specimen central during deformation. Specimens along the rolling direction (RD), diagonal direction (DD) and transverse direction (TD) respectively were prepared for each of the four types to study the effect of anisotropy on the deformation behavior. 
Table 1. Chemical compositions of QP980steel sheet (wt \%).

\begin{tabular}{ccccccccc}
\hline $\mathbf{C}$ & $\mathbf{S i}$ & $\mathbf{M n}$ & $\mathbf{P}$ & $\mathbf{S}$ & $\mathbf{A l}$ & $\mathbf{T i}$ & $\mathbf{N}$ \\
\hline 0.2089 & 1.386 & 1.876 & 0.0081 & 0.002 & 0.036 & 0.0061 & 0.0033 \\
\hline
\end{tabular}

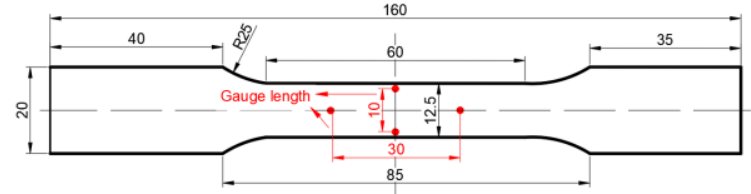

(a)

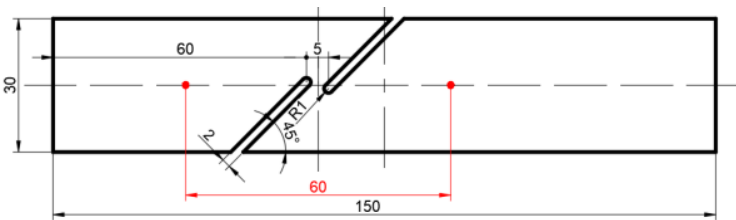

(c)

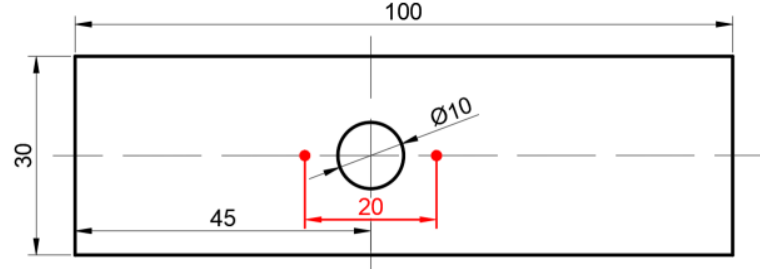

(b)

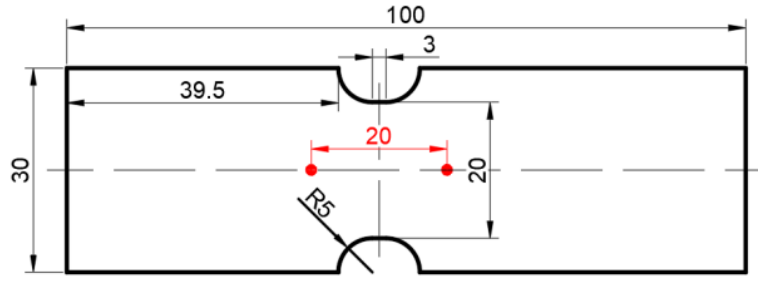

(d)

Figure 1. Four types of specimens [unit: $\mathrm{mm}$ ]: (a) dog-bone specimen; (b) specimen with a central hole; (c) in-plane shear specimen; (d) notched specimen.

\subsection{Tensile Tests}

Each specimen was stretched to ductile fracture by using a universal tensile testing machine with the maximum load capacity of $50 \mathrm{kN}$. In order to achieve a strain rate of $0.001 / \mathrm{s}$, particular tensile velocities were defined for different specimens, as shown in Table 2 [17]. The initial gauge lengths are illustrated in Figure 1 for different specimens. The deformation processes of the specimens painted with stochastic patterns (Figure 1) were recorded by using a XTOP digital image correlation (DIC) system at a framing rate of five per second.

Table 2. The applied tensile velocities for different specimens ( $\mathrm{mm} / \mathrm{min})$.

\begin{tabular}{ccccc}
\hline Specimen Type & $\begin{array}{c}\text { Dog-Bone } \\
\text { Specimens }\end{array}$ & $\begin{array}{c}\text { Specimens with } \\
\text { a Central Hole }\end{array}$ & $\begin{array}{c}\text { Notched } \\
\text { Specimens }\end{array}$ & $\begin{array}{c}\text { In-Plane Shear } \\
\text { Specimens }\end{array}$ \\
\hline Tensile velocity & 3.6 & 0.5 & 0.5 & 0.5 \\
\hline
\end{tabular}

\section{Experimental Results}

Figure 2 depicts experimental load-stroke response for dog-bone specimens along RD, $\mathrm{DD}$, and TD. The curves with good repeatability demonstrate that the anisotropic strength presents weak in the uniaxial tension. The true longitudinal strain and true width strain of the dog-bone specimens are calculated by DIC and GOM software with the initial gauge length denoted in Figure 1a. The relationships of the longitudinal and width strains of the dog-bone specimens along different loading directions are demonstrated in Figure 3. It shows that the anisotropy in plastic deformation is insignificant for QP980. Accordingly, the plastic behavior is approximately isotropic for QP980. 


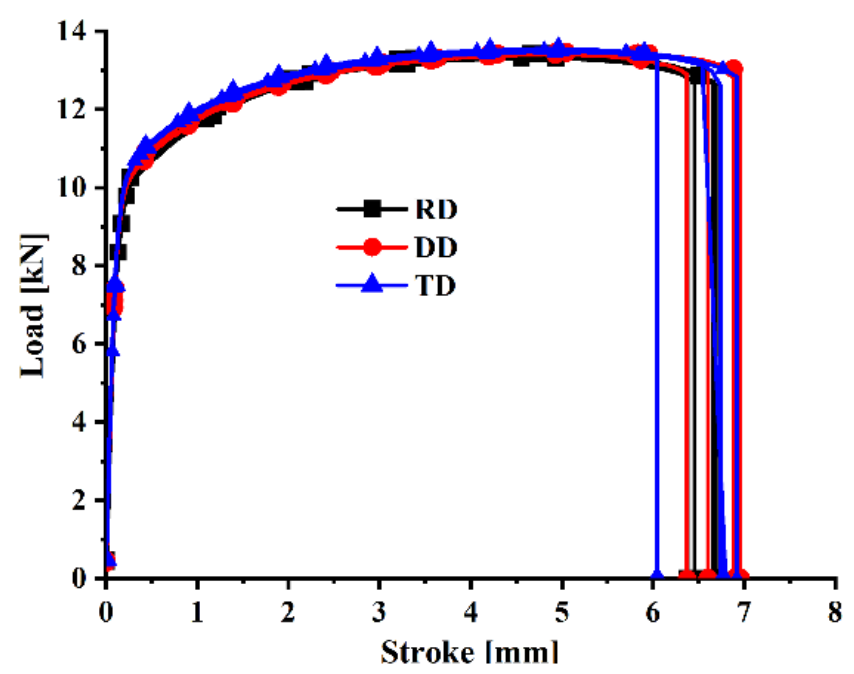

Figure 2. Stroke-load curves along different directions for dog-bone specimens.

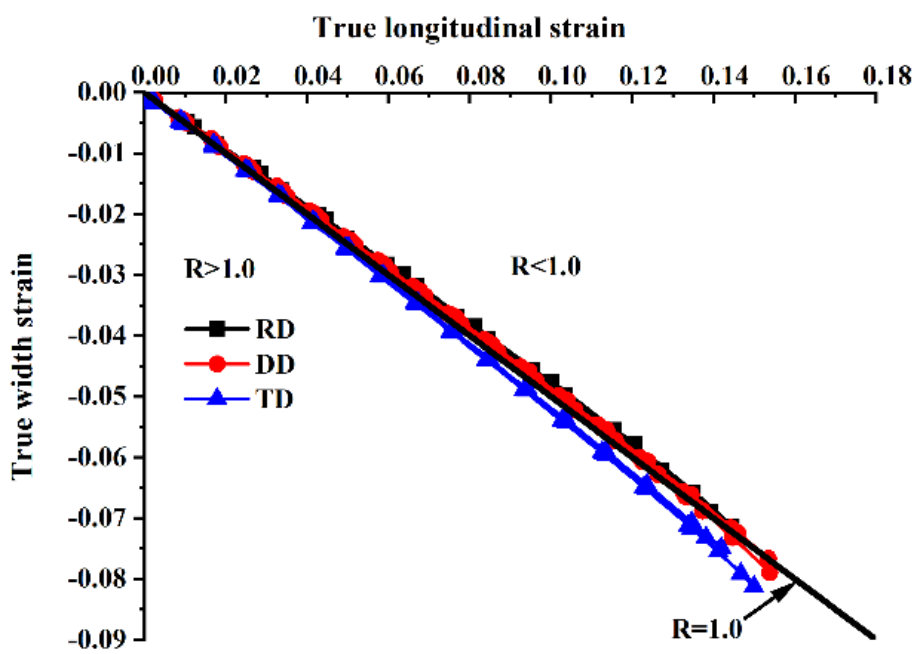

Figure 3. Anisotropy coefficients for the dog-bone specimens along different directions.

By analytical calculation of the load-stroke curve along RD in Figure 2, the strain hardening curve before necking, where the elastic strain is removed from the total strain, is depicted in Figure 4. The maximum plastic strain before necking is approximately 0.17 . The strain hardening curve is fitted by the Swift and Voce hardening laws as Equations (1)-(3) respectively, illustrating the hardening behavior with good consistency before necking. Nevertheless, the predicted results by using those two hardening laws are largely different after the necking strain. The Swift model predicts a higher loading capacity of the sheet metal than that obtained from the Voce model. Hence, the combined Swift-Voce model is used to modulate the predicted load capacity characterizing the strain hardening after necking. The parameters of the combined Swift-Voce model are shown in Table 3.

$$
\begin{gathered}
\text { Swift : } \sigma=K\left(\varepsilon_{\mathrm{p}}+\varepsilon_{0}\right)^{n} \\
\text { Voce : } \sigma=A-(A-B) \exp \left(-C \varepsilon_{\mathrm{p}}\right) \\
\text { Swift - Voce : } \sigma=\alpha \times K\left(\varepsilon_{\mathrm{p}}+\varepsilon_{0}\right)^{n}+(1-\alpha) \times\left[A-(A-B) \exp \left(-C \varepsilon_{p}\right)\right]
\end{gathered}
$$

where $K$ is the strengthen coefficient, $\mathrm{n}$ is the hardening exponent, and $A, B$, and $C$ are the material constants, $\varepsilon_{0}$ represents pre-strain, $\varepsilon_{p}$ denotes the equivalent plastic strain. 


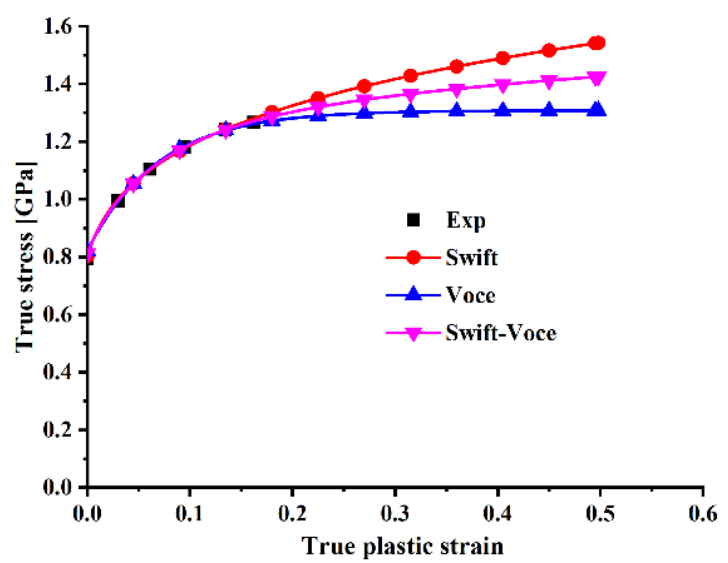

Figure 4. Stress-strain curves of the dog-bone specimens along the rolling direction.

Table 3. The parameters of the Swift-Voce model for QP980.

\begin{tabular}{ccccccc}
\hline $\boldsymbol{K}$ [GPa] & $\varepsilon_{0}$ & $\boldsymbol{n}$ & $\begin{array}{c}\text { Swift-Voce } \\
\boldsymbol{A} \text { [GPa] }\end{array}$ & $\boldsymbol{B}$ [GPa] & $\boldsymbol{C}$ & $\boldsymbol{\alpha}$ \\
\hline 1.72147 & 0.01096 & 0.16961 & 1.3144 & 0.82495 & 13.95224 & 0.5 \\
\hline
\end{tabular}

\section{Modeling of Plastic Deformation}

\subsection{Drucker Yield Function}

It is shown that the strength of materials is strongly affected by stress states [7]. A proper yield function should be selected to predict the effect of stress states on strength. Considering the isotropic strength of QP980, the pressure-coupled Drucker (P_Drucker) yield function [18] is used to model the plastic behavior under various loading conditions, including shear, uniaxial tension, and plane strain tension. Additionally, the $P$ _Drucker yield function couples the pressure effect into the Drucker yield function, which is expressed in terms of three stress invariants as:

$$
\bar{\sigma}_{P_{-} \text {Drucker }}\left(\sigma_{i j}\right)=a\left(b I_{1}+\left(J_{2}^{3}-c J_{3}^{2}\right)^{1 / 6}\right)
$$

where $I_{1}$ is the first stress tensor invariant, $J_{2}$ and $J_{3}$ are the second and third deviatoric stress tensor invariant, respectively, $a, b$, and $c$ are material constants. The application of the $P_{-}$Drucker function is to precisely describe the strain hardening behavior under various loading conditions.

$$
\begin{gathered}
I_{1}=\sigma_{11}+\sigma_{22}+\sigma_{33} \\
J_{2}=\frac{1}{6}\left[\left(\sigma_{11}-\sigma_{22}\right)^{2}+\left(\sigma_{22}-\sigma_{33}\right)^{2}+\left(\sigma_{33}-\sigma_{11}\right)^{2}\right]+\sigma_{12}^{2}+\sigma_{23}^{2}+\sigma_{13}^{2} \\
J_{3}=\operatorname{det}\left(s_{i j}\right)=s_{11} s_{22} s_{33}+2 s_{12} s_{23} s_{13}-s_{12}^{2} s_{33}-s_{23}^{2} s_{11}-s_{13}^{2} s_{22} \\
\bar{\sigma}=\sqrt{\frac{1}{2}\left[\left(\sigma_{1}-\sigma_{2}\right)^{2}+\left(\sigma_{2}-\sigma_{3}\right)^{2}+\left(\sigma_{3}-\sigma_{1}\right)^{2}\right]}
\end{gathered}
$$

Equation (8) is substituted into Equation (6) to describe the principal stresses as below:

$$
J_{2}=\frac{\bar{\sigma}^{2}}{3}
$$

The stress triaxiality $\eta$ and Lode parameter $L$ are defined as follows:

$$
\eta=\frac{\sigma_{m}}{\bar{\sigma}}=\frac{\sigma_{1}+\sigma_{2}+\sigma_{3}}{3 \bar{\sigma}}
$$




$$
L=\frac{2 \sigma_{2}-\sigma_{1}-\sigma_{3}}{\sigma_{1}-\sigma_{3}}
$$

Based on Equations (8), (10), and (11), the principal stresses can be presented by stress triaxiality $\eta$, Lode parameter $L$, and von Mises effective stress $\bar{\sigma}$ as follows:

$$
\begin{aligned}
& \sigma_{1}=\sigma_{m}+s_{1}=\sigma_{m}+\frac{(3-L) \bar{\sigma}}{3 \sqrt{3+L^{2}}}=\left(\eta+\frac{3-L}{3 \sqrt{3+L^{2}}}\right) \bar{\sigma} \\
& \sigma_{2}=\sigma_{m}+s_{2}=\sigma_{m}+\frac{2 L \bar{\sigma}}{3 \sqrt{3+L^{2}}}=\left(\eta+\frac{2 L}{3 \sqrt{3+L^{2}}}\right) \bar{\sigma} \\
& \sigma_{3}=\sigma_{m}+s_{3}=\sigma_{m}-\frac{(3+L) \bar{\sigma}}{3 \sqrt{3+L^{2}}}=\left(\eta-\frac{3+L}{3 \sqrt{3+L^{2}}}\right) \bar{\sigma}
\end{aligned}
$$

According to Equations (12)-(14), Equation (7) can be transformed as follows:

$$
J_{3}=\left|s_{i j}\right|=s_{1} s_{2} s_{3}=\frac{-2 L\left(9-L^{2}\right)}{27\left(L^{2}+3\right)^{3 / 2}} \bar{\sigma}^{3}
$$

Equation (10) is substituted into Equation (5) in the form of principal stress

$$
I_{1}=3 \eta \bar{\sigma}
$$

Based on Equations (9), (15), and (16), Equation (4) can be transformed as a function of $\eta$, $\mathrm{L}$, and $\bar{\sigma}$ as below:

$$
\begin{gathered}
\bar{\sigma}_{P_{-} \text {Drucker }}\left(\sigma_{i j}\right)=a\left[3 b \eta+\left(\frac{1}{27}-c \frac{4 L^{2}\left(9-L^{2}\right)^{2}}{729\left(L^{2}+3\right)^{3}}\right)^{1 / 6}\right] \bar{\sigma} \\
a=\frac{1}{b+\frac{1}{3}(27-4 c)^{1 / 6}}
\end{gathered}
$$

Based on the stress-strain curves obtained by uniaxial tensile tests in Figure 5, the material constant $a$ is determined by Equation (18) as 1.837. The material constants $b$ and $c$ are defined as 0 and 2.0 respectively [18].

\subsection{Element Size Sensitivity}

The Swift-Voce hardening model and $P \_D r u c k e r$ function are programmed into VUMAT subroutine to predict the deformation processes of QP980 under complex stress states. In order to improve the calculation efficiency, only one-eighth of a dog-bone specimen, a specimen with a central hole and a notched specimen, and a half of an in-plane shear specimen are built as the simulation model. The symmetric boundary conditions are then forced in the simulations with respect to the $x-y, y-z$ and $x-z$ planes for the dog-bone specimen, notched specimen, and the specimen with a central hole. Symmetric boundary condition is applied for the in-plane shear specimen since a half model along the thickness is used for simulation of this test as shown in Figure 6d. Then constant velocity is applied to the fixed end of the specimens according to the tensile velocity in the tests. The mesh type is C3D8R, and the mesh refinement is defined on the deformation concentrated area of the specimens. The element size sensitivity is studied by comparing the experimental and simulated loadstroke curves with six different element sizes for all the specimens, of which the notched specimen is shown in Figure 5. The number of element layers along thickness increases from one to five from set \#1 to set \#5. The number of elements for each layer is identical to that in set \#1. The finite element model of set \#6 has five layers along the thickness, but the number of elements in each layer is 1.5 times of set \#1. The comparison of the load-stroke curves in Figure $5 b$ indicates that the force response is insensitive to the element size. The local strain evolution at the center of the notched specimen is compared with experimental 
results. It is observed that element size does not affect the local deformation significantly. Because the parameter optimization by the inverse engineering approach needs to conduct the simulation for dozens of times, the reduction of simulation time is very important for the inverse engineering approach. Consequently, Set \#1 is selected as the element model for the notched specimens to improve the numerical simulation efficiency. By using the similar element size analysis, the finite element models for other shaped specimens are determined, as shown in Figure 6.

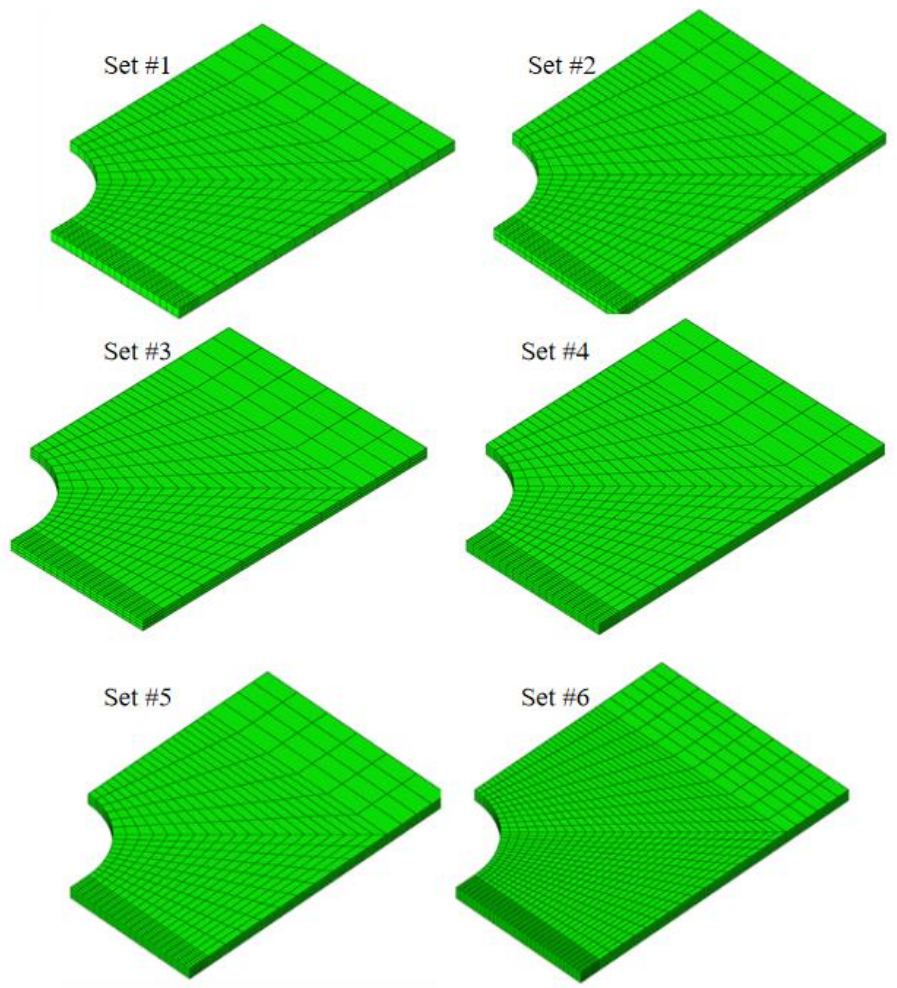

(a)

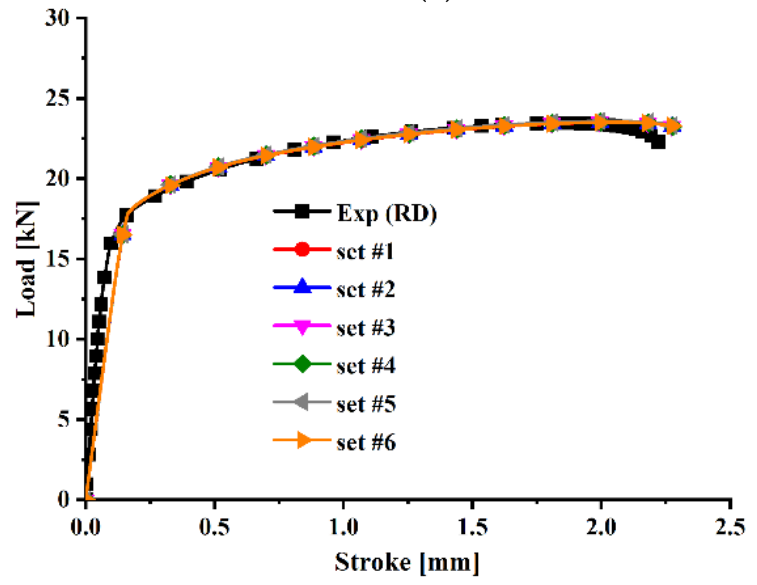

(b)

Figure 5. Cont. 


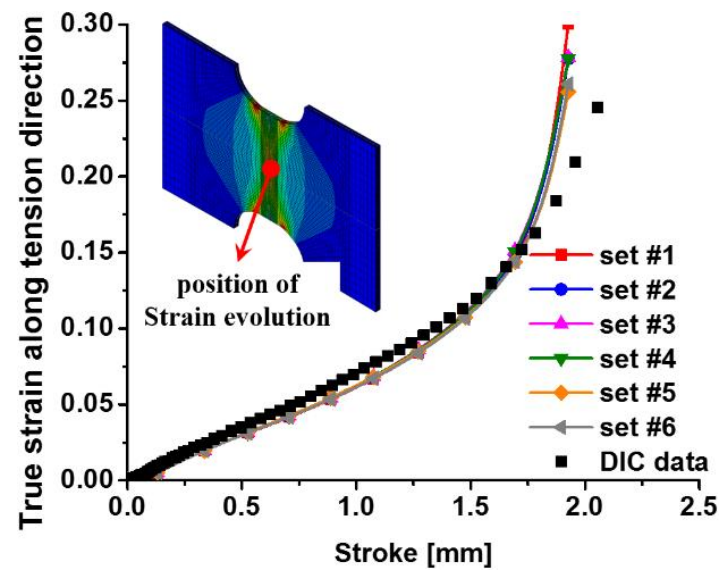

(c)

Figure 5. Analysis of element size sensitivity for the notched specimen: (a) finite element modelled meshing for the notched specimen; (b) comparisons between the experimental and simulated loadstroke curves for the notched specimen; (c) local strain evolution along the tension direction for the notched specimens.

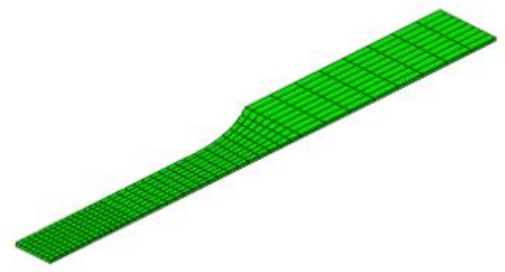

(a)

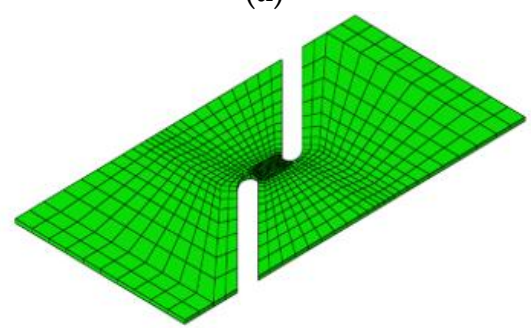

(c)

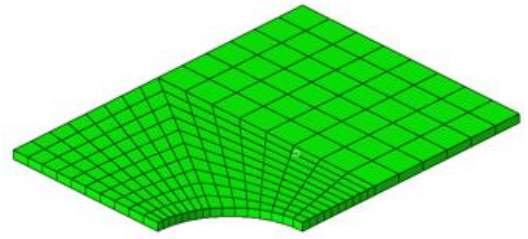

(b)

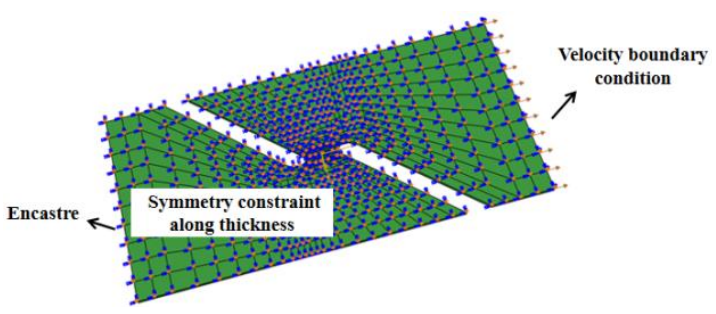

(d)

Figure 6. The finite element model: (a) the dog-bone specimen; (b) the specimen with a central hole; (c) the in-plane shear specimen; (d) the boundary conditions of the in-plane shear specimen.

\subsection{Calibration of the Constitutive Model Parameters by Using the Inverse Engineering}

The finite element models in Section 4.2 are used to simulate the load-stroke response of the four shaped specimens along RD, DD, and TD, respectively. The combined SwiftVoce hardening law as shown in Equation (3) is utilized to characterize the strain hardening of the material. The von Mises and P_Drucker yield function are used to model the yielding phenomena under various arbitrary stress states. The experimental and simulated loadstroke curves of the four shaped specimens along RD are compared in Figure 7. The load errors predicted by the two yield functions are calculated for simulation along different loading directions according to Equations (19) and (20) as shown in Figure 8. The prediction errors of the two yield functions are approximately similar for the dog-bone specimen and the specimen with a central hole along RD, DD, and TD. For the notched specimens, the results by the $P \_$Drucker yield function is slightly lower than that predicted by the von Mises yield function along DD and TD. The error values of in-plane shear specimens of the P_Drucker function is observed to be much smaller than the von Mises function. Comparing 
the total error values, it can be seen that the total error values of $P_{-}$Drucker yield function are all lower than that of von Mises yield function, and the prediction accuracy of $P_{-}$Drucker yield function is about $15 \%$ higher than that of von Mises yield function.

$$
\begin{gathered}
\text { err }_{m}=\sqrt{\sum_{i=1}^{n}\left(\frac{F_{i}^{\mathrm{exp}}-F_{i}^{\text {sim }}}{F_{a v e}^{\mathrm{exp}}}\right)^{2}} \\
\text { Total }_{\text {err }}=\sum \mathrm{err}_{m}
\end{gathered}
$$

where $n$ is the number of data point, $F_{i}^{\exp }$ and $F_{i}^{\text {sim }}$ are the experimental load and simulated load of $i$ data point, $F_{\text {ave }}^{\text {exp }}$ is the average value of experimental load.

Although $P_{-}$Drucker yield function increases the prediction accuracy of the plastic deformation of QP980 compared to von Mises yield function, the predicted load values by $P_{-}$Drucker yield function for the specimens with a center hole are higher than the experimental values. However, the predicted load values by $P_{-}$Drucker yield function for notched specimens are lower than the experimental values. To accurately clarify the material strength of QP980 under complex stress states, the inverse engineering (IE) is used to calibrate the constitutive model parameters. As the model parameter correction method combining experiment and numerical simulation, IE has been widely used in many fields. By constantly optimizing the parameters of the constitutive model by IE, the error between the simulated and the experimental results is minimized according to Equation (19), thus obtaining the optimal parameters of the constitutive model. The optimization algorithm used in IE is Newton downhill method. The optimization process of IE is illustrated in Figure 9.
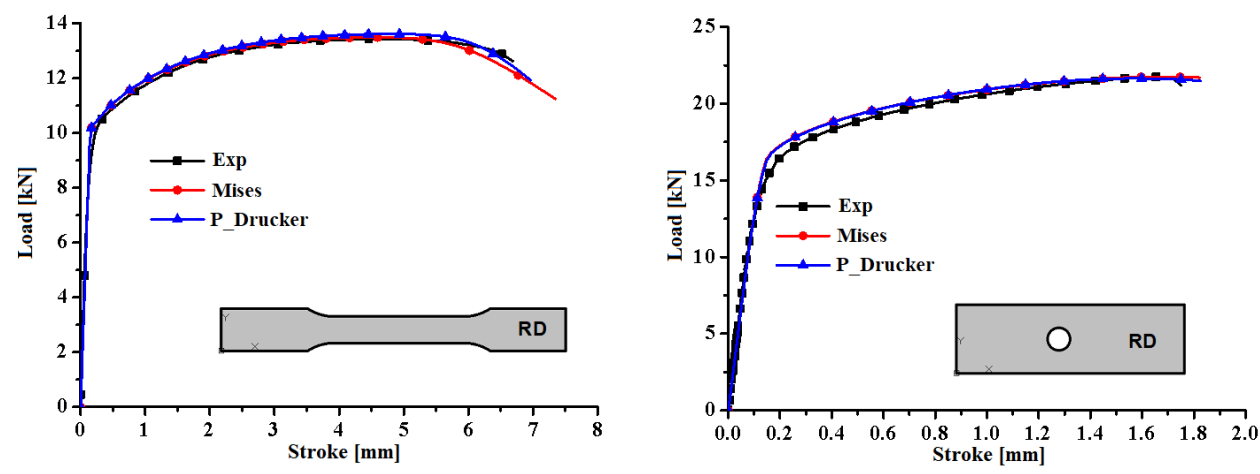

(a)

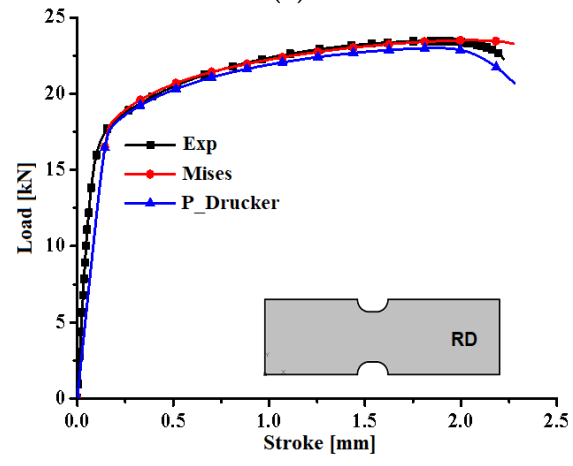

(b)

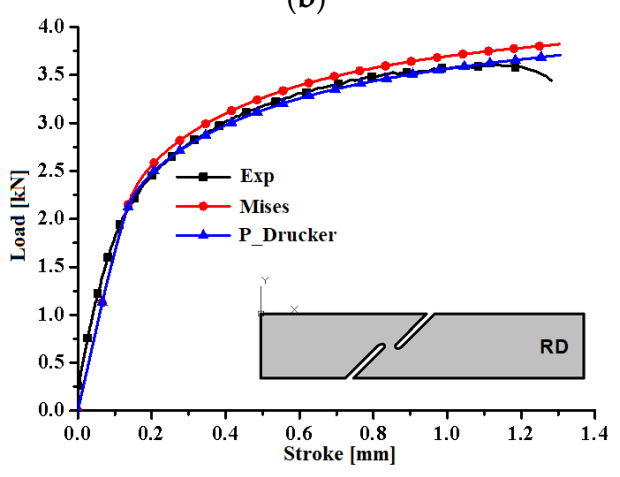

(c)

(d)

Figure 7. The comparison of the load-stroke curves between the experiment and simulation obtained from different yield functions along RD: (a) the dog-bone specimen; (b) the specimen with a central hole; (c) the notched specimen; (d) the in-plane shear specimen. 


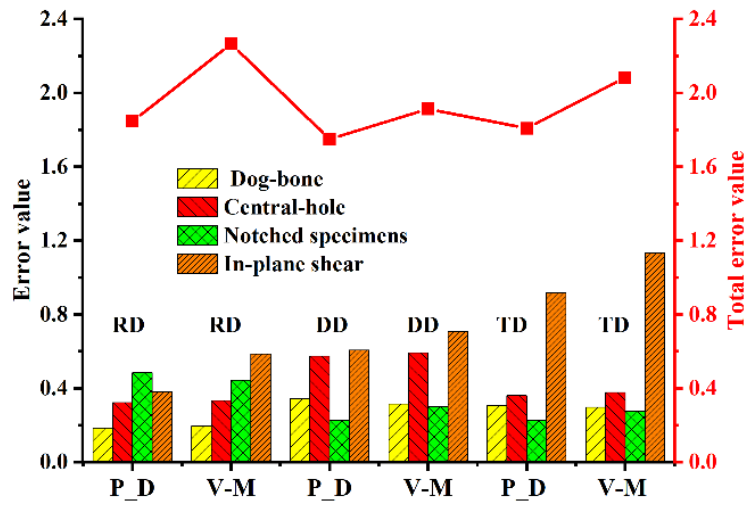

Figure 8. Error values predicted by $P_{-}$Drucker yield function and von Mises yield function.

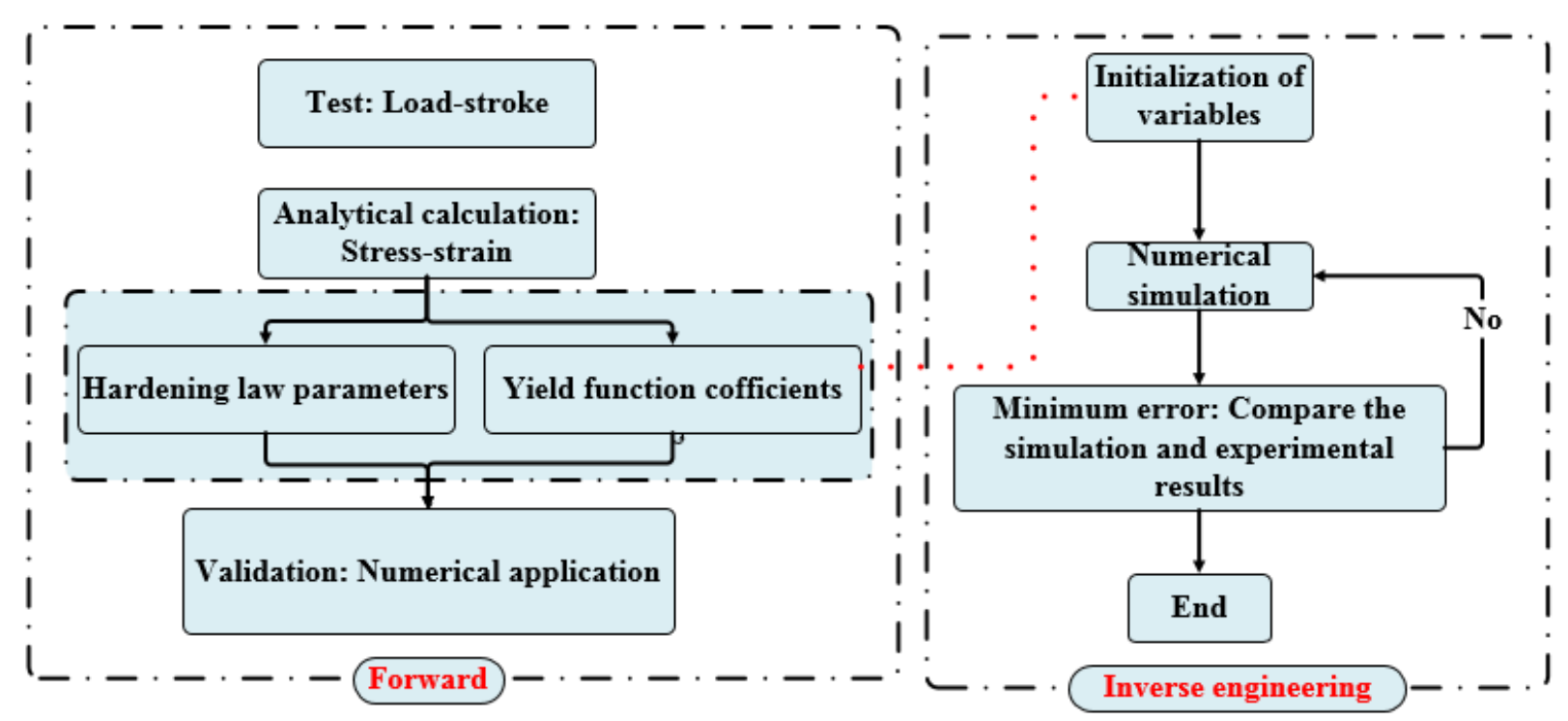

Figure 9. The optimization process of the inverse engineering.

The $P \_$Drucker yield function has better prediction accuracy than the von Mises yield function. Hence, the parameters of the combined Swift-Voce model and the P_Drucker yield function are calibrated by IE. Considering dog-bone specimen along RD as the optimization model of IE, the optimized constitutive model parameters are summarized in Table 4 . The optimized constitutive model parameters are used to simulate the load-stroke curves for the specimen with a central hole, the notched specimen, and the in-plane shear specimen. Figure 10 presents the predicted load capability after optimization with better fitting to the experimental values, decreasing the deviation of the $P_{-}$Drucker yield function in the numerical simulation of the specimen with a center hole and the notched specimen. The error comparison in Figure 11 demonstrates that the constitutive model optimized by IE can accurately characterize the strain hardening behavior of QP980.

Table 4. Constitutive model optimization by inverse engineering.

\begin{tabular}{|c|c|c|c|c|c|c|c|c|c|c|}
\hline \multirow{2}{*}{ Parameters } & \multicolumn{3}{|c|}{ P_Drucker } & \multicolumn{7}{|c|}{ Swift-Voce } \\
\hline & $a$ & $b$ & $c$ & $K$ [GPa] & $\varepsilon_{0}$ & $n$ & $A[\mathrm{GPa}]$ & $B$ [GPa] & $C$ & $\alpha$ \\
\hline Initial value & 1.837 & 0.0 & 2.0 & 1.721 & 0.011 & 0.170 & 1.314 & 0.825 & 13.952 & 0.5 \\
\hline Optimized value & 1.821 & 0.002 & 1.870 & 1.750 & 0.014 & 0.190 & 1.380 & 0.778 & 14.175 & 0.5 \\
\hline
\end{tabular}

The maximum value and distribution of the equivalent plastic strain obtained from the simulation by using the optimized constitutive model are close to those measured by 
DIC, as shown in Figure 12. On the basis of the equivalent plastic strain distribution, the equivalent plastic strain of Node A in numerical simulation is extracted and then compared with DIC measurement, as shown in Figure 13. The error between the simulated and DIC measured equivalent plastic strains of the notched specimen, as shown in Figure 13b, is found to be less than $5 \%$. The comparison further reveals that the strain hardening behavior of those specimens can be accurately characterized by using the combined Swift-Voce hardening model and P_Drucker yield function, and the IE can effectively enhance the prediction accuracy.

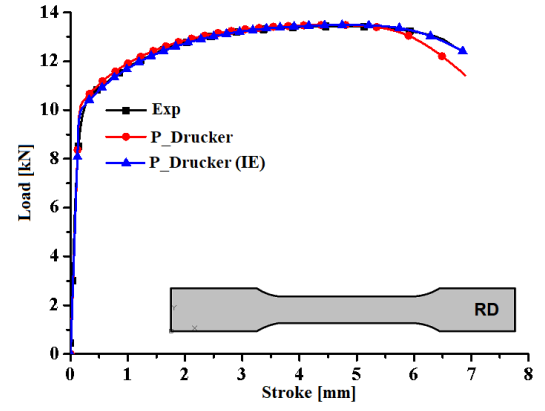

(a)

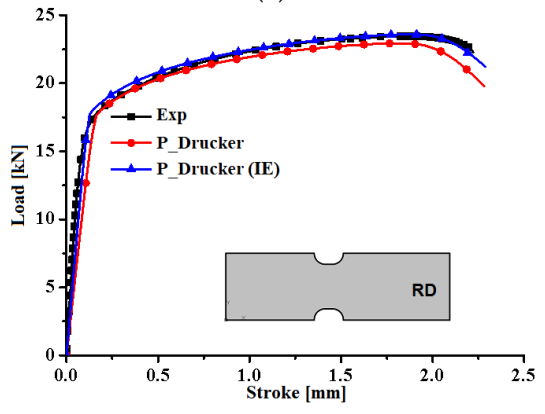

(c)

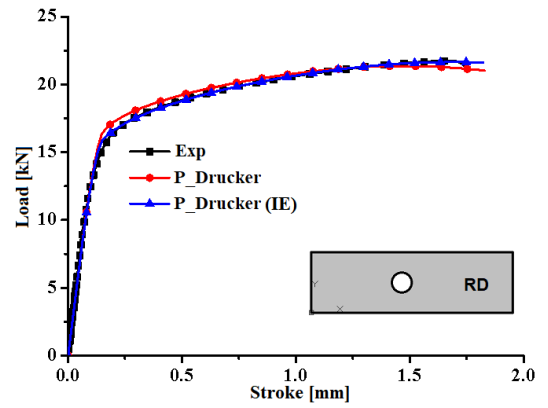

(b)

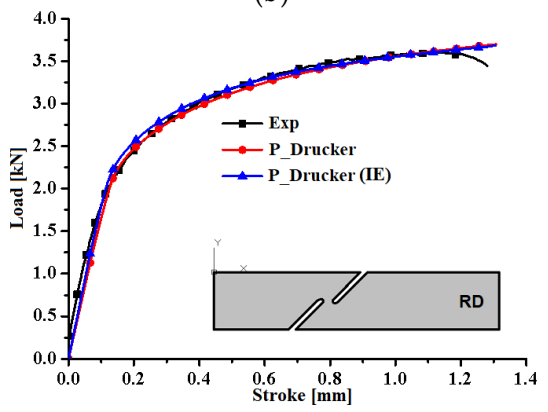

(d)

Figure 10. Comparisons of the load-stroke curves between the experiments and simulations after the inverse engineering optimization: (a) dog-bone specimen; (b) specimen with a central hole; (c) notched specimen; (d) in-plane shear specimen.

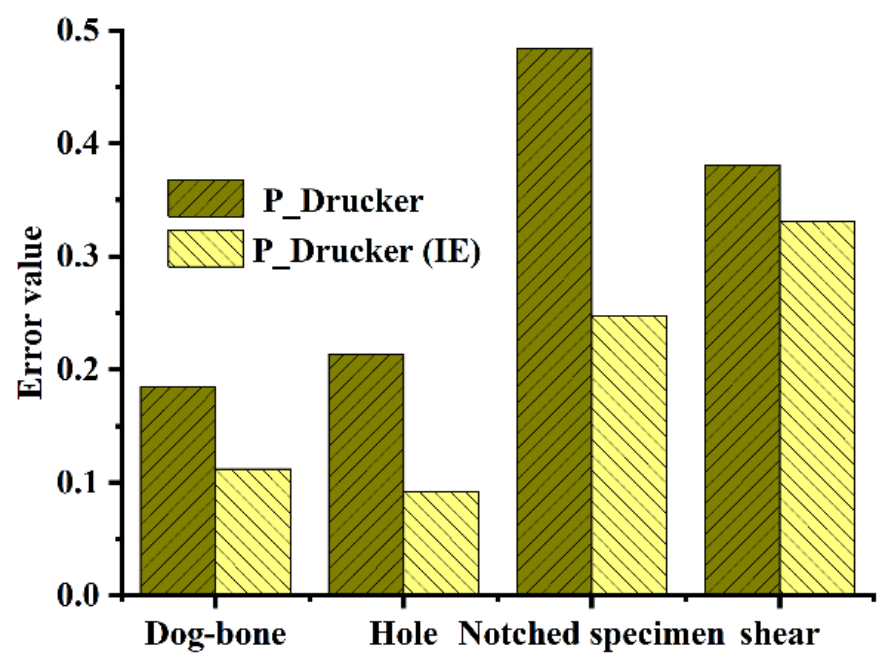

Figure 11. Comparison of the prediction error value before and after parameter optimization. 


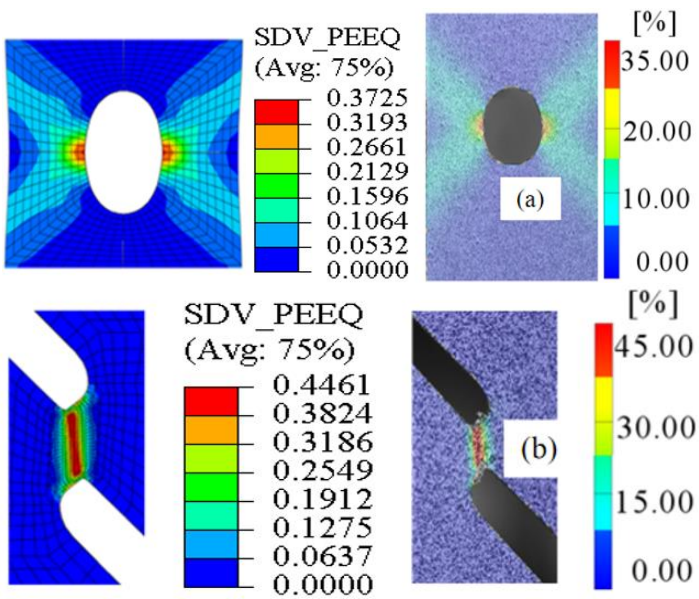

Figure 12. Comparisons between the simulated equivalent strain and the DIC equivalent strain: (a) specimen with a central hole; (b) in-plane shear specimen.

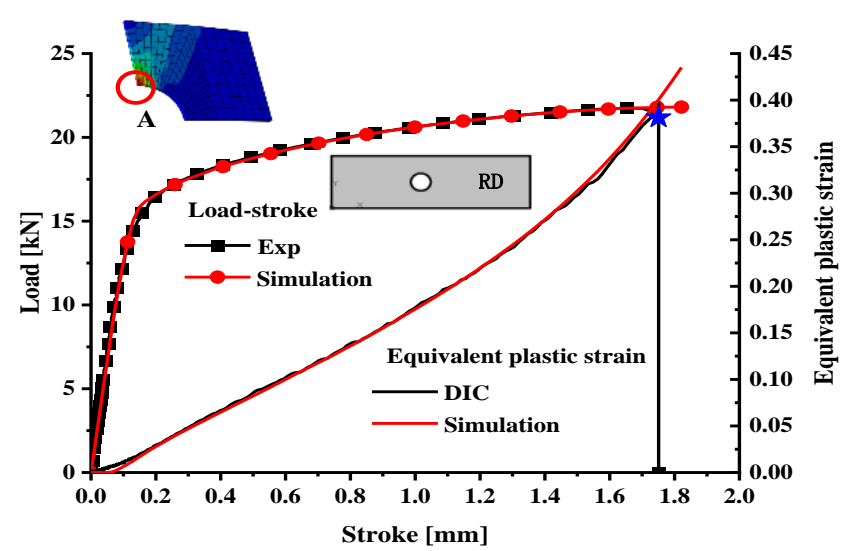

(a)

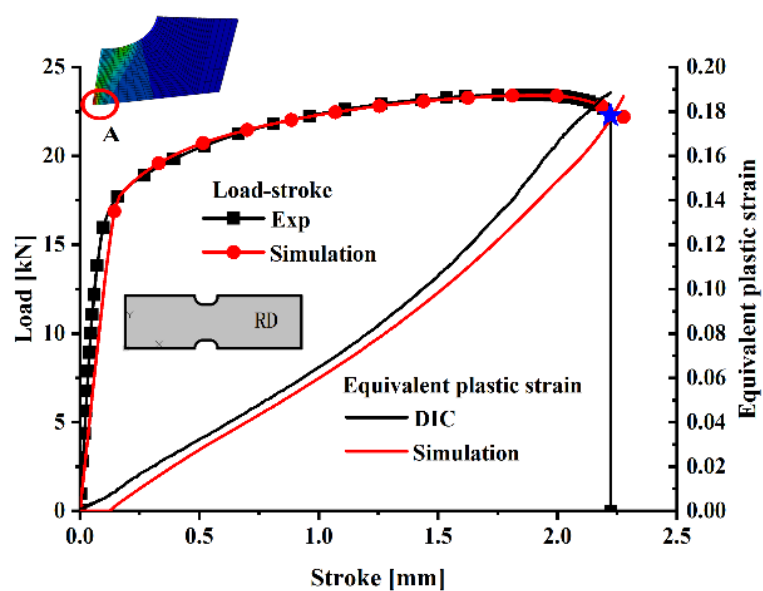

(b)

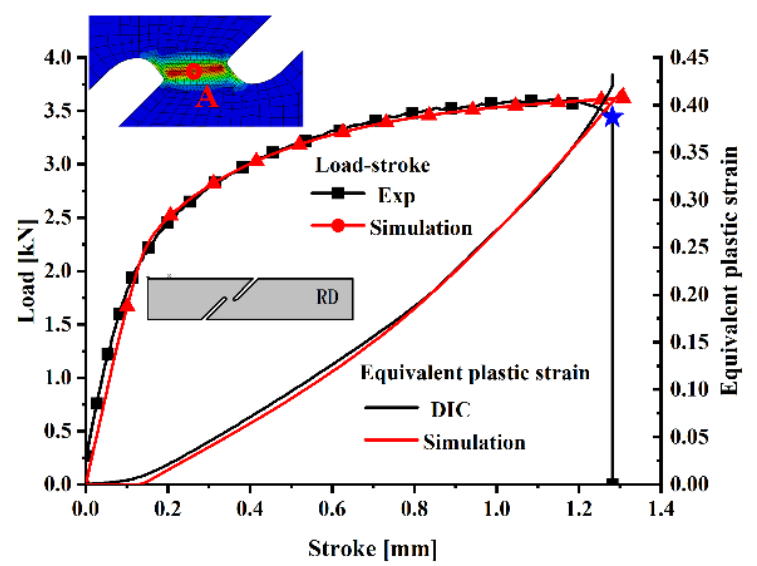

(c)

Figure 13. Comparisons of the experimental and simulated equivalent plastic strain to fracture: (a) specimen with a central hole; (b) notched specimen; (c) in-plane shear specimen.

According to the experimental load-stroke curves shown in Figure 13a-c, the stroke that drop of load capability is clearly observed is defined as the fracture stroke, and the equivalent strain at the fracture stroke is defined as the fracture strain that is marked by blue pentagram. The ductile fracture strains of the three shaped specimens are summarized in Table 5. 
Table 5. Equivalent fracture strains of specimens, average stress triaxiality and lode parameters of different shaped specimens along RD.

\begin{tabular}{cccc}
\hline Specimens & $\begin{array}{c}\text { Specimen with a } \\
\text { Central Hole }\end{array}$ & Notched Specimen & In-Plane Shear \\
\hline Plastic fracture strain & 0.385 & 0.1865 & 0.419 \\
Lode parameter & -0.861 & -0.333 & -0.283 \\
Stress triaxiality & 0.375 & 0.547 & 0.107 \\
\hline
\end{tabular}

\section{Fracture Prediction}

The accurate prediction of the fracture in sheet metal forming requires an appropriate ductile fracture criterion as well as a proper parameter calibration. The uncoupled ductile fracture criterion is widely used to predict the ductile fracture of sheet metals during the forming processes. However, the traditional uncoupled ductile fracture criteria generally do not take the effect of the stress states into account, resulting in a consequence that the prediction accuracy is not promising in a wide range of stress triaxiality [19]. In this research, the fracture is modeled by a shear-controlled ductile fracture criterion which is proposed based on the micro-mechanism of the ductile fracture for nucleation, growth, and coalescence of voids [3]. The ductile fracture criterion is referred to as DF2012 as below:

$$
\left(\frac{2 \tau_{\max }}{\bar{\sigma}}\right)^{C_{1}}\left(\frac{\langle 1+3 \eta\rangle}{2}\right)^{C_{2}} \bar{\varepsilon}_{f}^{p}=C_{3},\langle x\rangle=\left\{\begin{array}{l}
x, x \geq 0 \\
0, x<0
\end{array}\right.
$$

where $\eta$ is stress triaxiality and $\tau_{\max }$ is maximum shear stress.

The traditional uncoupled ductile fracture criteria used in this section are summarized as below:

Ko-Huh criterion [20]:

$$
\int_{0}^{\bar{\varepsilon}_{f}} \frac{\sigma_{1}}{\bar{\sigma}}\left\langle 1+\frac{3 \sigma_{m}}{\bar{\sigma}}\right\rangle d \bar{\varepsilon}=C_{4}\langle x\rangle=\left\{\begin{array}{l}
x \text { when } x \geq 0 \\
0 \text { when } x<0
\end{array}\right.
$$

Brozzo criterion [21]:

$$
\int_{0}^{\bar{\varepsilon}_{f}} \frac{2 \sigma_{1}}{3\left(\sigma_{1}-\sigma_{m}\right)} d \bar{\varepsilon}=C_{5}
$$

Oh criterion [22]:

$$
\int_{0}^{\bar{\varepsilon}_{f}} \frac{\sigma_{1}}{\bar{\sigma}} d \bar{\varepsilon}=C_{6}
$$

Rice-Tracey criterion [23]:

$$
\int_{0}^{\bar{\varepsilon}_{f}} 0.283 \exp \left(\frac{3 \sigma_{m}}{2 \bar{\sigma}}\right) d \bar{\varepsilon}=C_{7}
$$

DF2012 and the traditional uncoupled ductile fracture criteria, namely Ko-Huh criterion, Brozzo criterion, Oh criterion, and Rice-Tracey criterion, are respectively used to predict the ductile fracture of QP980 under the complex stress states. The stress triaxiality, Lode parameters, and equivalent plastic strain from the initiation of plastic strain to fracture in the numerical simulation are shown in Figure $14 \mathrm{a}-\mathrm{c}$, the extraction positions of these parameters are depicted in Node A of Figure 13. It is observed that the stress state is approximately proportional for the specimen with a central hole. There is a slight rise in the Lode parameter. The stress state evolution is very strong for the in-plane shear specimen. It is a big challenge to characterize the plasticity and fracture behavior under shear. Different experimental methods were developed to characterize mechanical behavior under shear for sheet metals, such as torsion tests. Zhang et al. [7] combined the in-plane torsion test with an inverse engineering approach to characterize shear flow curves up to large strain. Even though the torsion tests perform better than in-plane shear specimen to 
characterize mechanical properties under shear, the specimen geometry and test machine are complicated for the torsion test. Therefore, the in-plane shear specimen is the simplest method to characterize the shear properties of sheet metals by experiments. The average stress triaxiality and Lode parameter of three shaped specimens are calculated by Equations (26) and (27) and then summarized in Table 5.

$$
\begin{aligned}
& \eta_{\text {ave }}=\frac{1}{\bar{\varepsilon}_{f}} \int_{0}^{\bar{\varepsilon}_{f}} \eta(\bar{\varepsilon}) d \bar{\varepsilon} . \\
& L_{\text {ave }}=\frac{1}{\bar{\varepsilon}_{f}} \int_{0}^{\bar{\varepsilon}_{f}} L(\bar{\varepsilon}) d \bar{\varepsilon}
\end{aligned}
$$

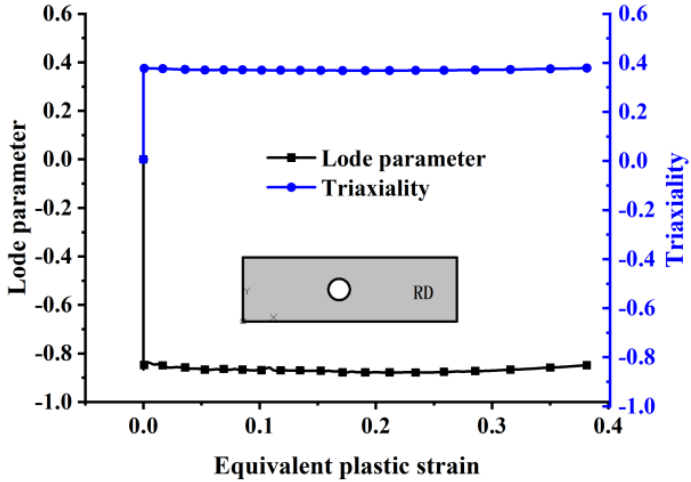

(a)

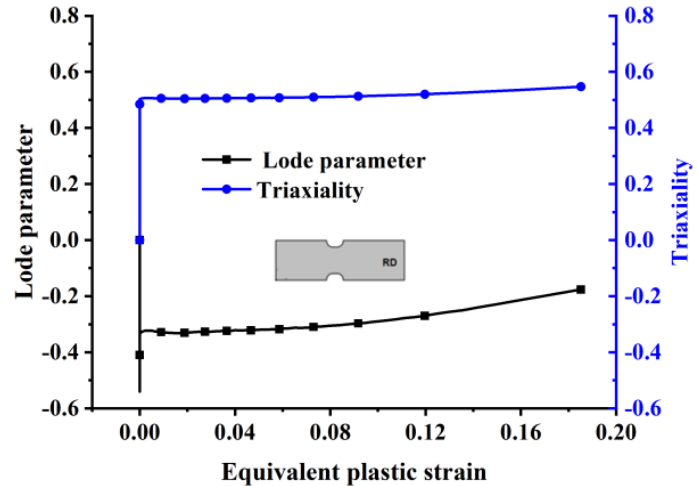

(b)

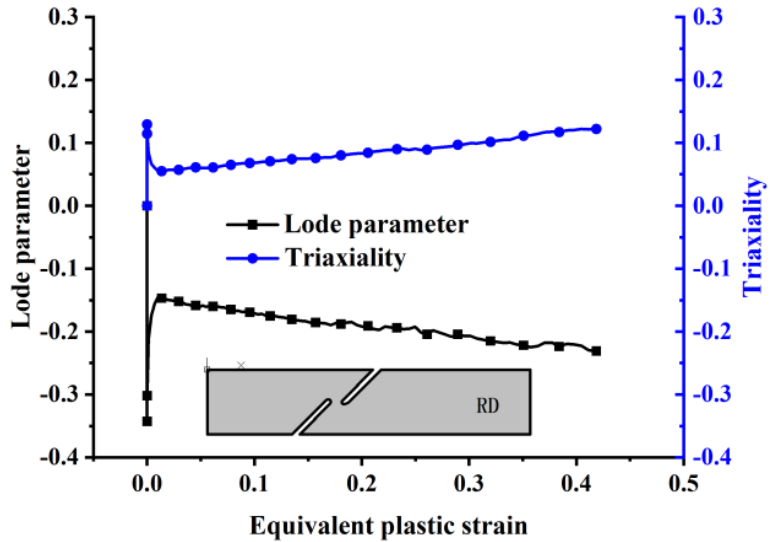

(c)

Figure 14. Evolution of stress triaxiality and Lode parameter with equivalent plastic strain: (a) specimen with a central hole; (b) notched specimen; (c) in-plane shear specimen.

The results in Table 5 are used to calibrate the material constants in the ductile fracture criterion, denoted as Table 6. Based on the optimized constitutive model of Section 4.3, those ductile fracture criteria are conducted to predict the ductile fracture of QP980 under complex stress states. The minimum difference between the experimental and the simulated fracture stroke are employed to calibrate the ductile fracture criterion parameters by using IE, as shown in Table 6. The comparison of the stroke-load curves between the experiments and simulations is plotted in Figure 15a-c. The prediction accuracy of the DF2102 criterion is significantly higher than that of the traditional uncoupled ductile fracture criteria. The prediction errors of the different fracture criteria are expressed in Figure 16. The prediction error of DF2012 by IE is the lowest, compared to the traditional uncoupled ductile fracture criteria. This is because the influences of the hydrostatic stress, equivalent stress and maximum principal stress are considered in the traditional uncoupled ductile fracture 
criteria, and those mechanical variables are closely related to stress triaxiality. Bao et al. [24] found that the fracture mechanisms depends on the stress triaxiality ranges. The influence of the stress triaxiality and normalized maximum shear stress $\left(\tau_{\max } / \bar{\sigma}\right)$ are considered in DF2012. Hence, DF2012 can effectively predict the ductile fracture of QP980 during the forming processes. The fracture locus of QP980 predicted by DF2012 and the traditional uncoupled ductile fracture criteria is depicted in Figure 17. The comparison in Figure 17b shows that DF2012 can describe the fracture behavior of QP980 in a wide range of stress triaxiality, and the ductile fracture of sheet metal needs to consider the influence of stress triaxiality and Lode parameters.

Table 6. The material constants in the ductile fracture criterion.

\begin{tabular}{ccccccccc}
\hline \multirow{2}{*}{ Parameters } & \multicolumn{3}{c}{ DF2012 } & & Ko-Huh & Brozzo & Oh & Rice-Tracey \\
\cline { 2 - 8 } & $C_{1}$ & $C_{2}$ & $C_{3}$ & $C_{4}$ & $C_{5}$ & $C_{6}$ & $C_{7}$ \\
\hline Initial value & 1.2281 & 2.1675 & 0.4497 & 1.2299 & 0.6580 & 0.6066 & 0.2574 \\
Optimized value & 1.2737 & 2.0143 & 0.4499 & 0.8593 & 0.4593 & 0.4499 & 0.2039 \\
\hline
\end{tabular}

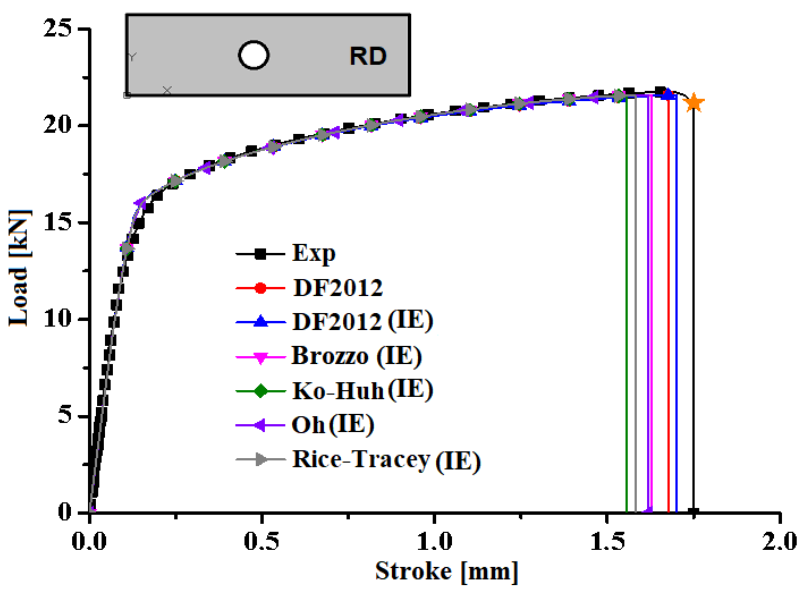

(a)

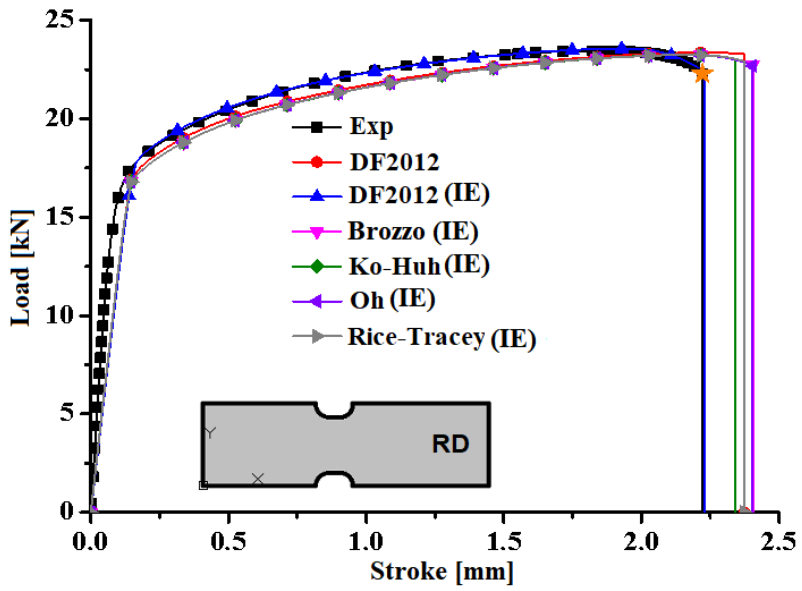

(b)

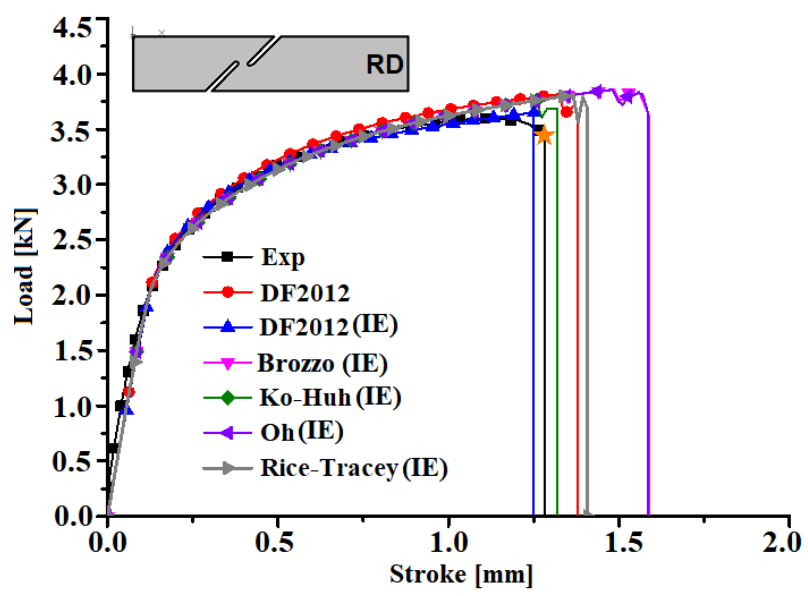

(c)

Figure 15. The stroke-load curves predicted by the ductile fracture criteria: (a) specimen with a central hole; (b) notched specimen; (c) in-plane shear specimen. 


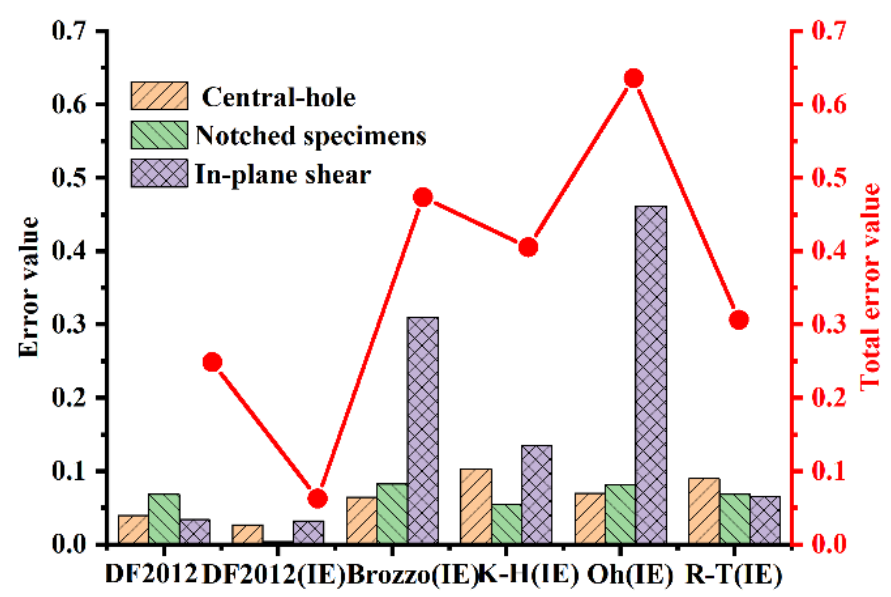

Figure 16. Error comparison of load-stroke predicted by different ductile fracture criteria.

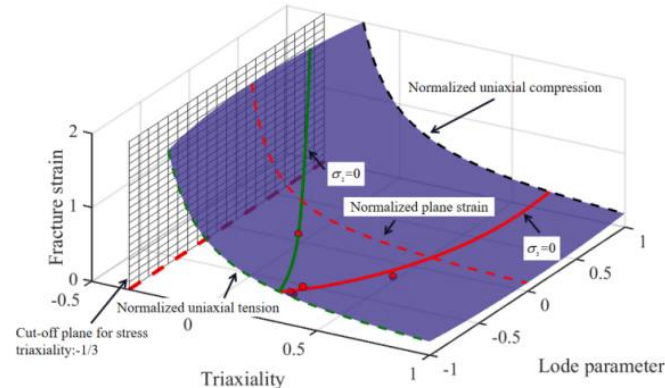

(a)

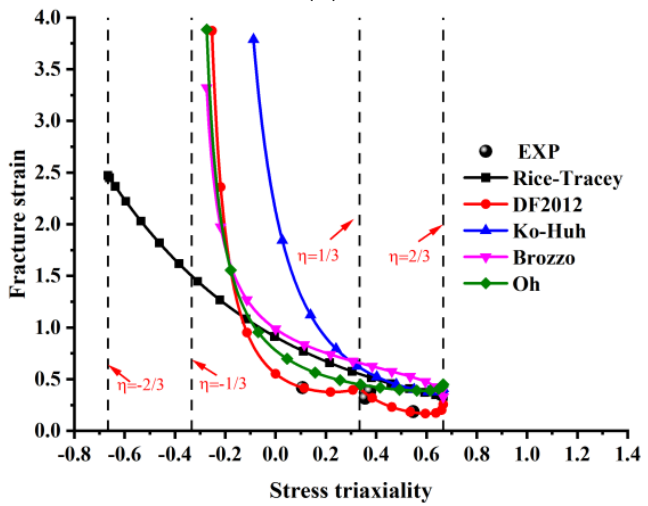

(b)

Figure 17. The fracture locus of QP980: (a) in the space of $\left(\eta, L, \bar{\varepsilon}_{f}\right)$ predicted by DF2012; (b) in the space of $\left(\eta, \bar{\varepsilon}_{f}\right)$ predicted by the traditional uncoupled ductile fracture criteria and DF2012.

\section{Conclusions}

This research characterizes the failure of QP980 sheet metals under wide stress states from shear to plane strain tension by experiments, analytical modeling, and numerical simulation. It is found that the four specimens used in this study are proper to measure the fracture strain under different stress states of shear, uniaxial tension, and plane strain tension. The $P_{-}$Drucker yield function with the Swift-Voce hardening law is shown to be capable of precise modeling of plastic response of QP980 from the onset of plastic deformation to fracture at different stress states. The DF2012 criterion is observed to predict the onset of ductile fracture with good agreement compared with experiments. The predicting accuracy of the constitutive models is strongly dependent on the calibration of the material constants in the constitutive models. The strain hardening law, yield function, and fracture criterion are recommended to be calibrated by the inverse engineering 
approach to improve the performance of the constitutive models and the reliability of numerical simulations.

Author Contributions: Writing-original draft preparation, formal analysis, S.W.; methodology, software, validation, data curation, Y.W.; writing-review and editing, L.Y.; writing-review and editing, K.J.; writing-review and editing, X.L.; conceptualization, supervision, writing-review and editing, project administration, Y.L. All authors have read and agreed to the published version of the manuscript.

Funding: This research was funded by the National Natural Science Foundation of China, grant number 52075423 and U2141214.

Institutional Review Board Statement: Not applicable.

Informed Consent Statement: Not applicable.

Data Availability Statement: The data presented in this study are available on request from the corresponding author.

Conflicts of Interest: The authors declare no conflict of interest.

\section{References}

1. Senuma, T. Advances in physical metallurgy and processing of steels. Physical Metallurgy of Modern High Strength Steel Sheets. ISIJ Int. 2001, 41, 520-532. [CrossRef]

2. Zhang, W.C. Study on Dynamic Constitutive Equation and Fracture of QP980 Steel Coupling with Phase Transformation. Master's Thesis, Ningbo University, Ningbo, China, 2017.

3. Lou, Y.S.; Huh, H.; Lim, S.; Pack, K. New ductile fracture criterion for prediction of fracture forming limit diagrams of sheet metals. Int. J. Solids Struct. 2012, 49, 3605-3615. [CrossRef]

4. Lou, Y.S.; Huh, H. Extension of a shear-controlled ductile fracture model considering the stress triaxiality and the Lode parameter. Int. J. Solids Struct. 2013, 50, 447-455. [CrossRef]

5. Li, H.; Fu, M.W.; Lu, J.; Yang, H. Ductile fracture: Experiments and computations. Int. J. Plast. 2011, 27, 147-180. [CrossRef]

6. Bai, Y.; Wierzbicki, T. Application of extended Mohr-Coulomb criterion to ductile fracture. Int. J. Fract. 2010, 161, 1. [CrossRef]

7. Zhang, C.; Lou, Y.S.; Zhang, S.J.; Clausmeyer, T.; Tekkaya, A.E.; Fu, L.; Chen, Q.; Zhang, Q. Large strain flow curve identification for sheet metals under complex stress states. Mech. Mater. 2021, 161, 103997. [CrossRef]

8. Luo, S.L.; Yang, G.; Lou, Y.S.; Xu, Y.Q. Prediction of strain path changing effect on forming limits of AA 6111-T4 based on a shear ductile fracture criterion. Metals 2021, 11, 546. [CrossRef]

9. Ghadikolaee, H.T.; Naeini, H.M.; Mirna, M.J.; Gorji, H.; Alexandrov, S. Fracture analysis on U-bending of AA6061 aluminum alloy sheet using phenomenological ductile fracture criteria. Thin-Walled Struct. 2020, 148, 106566. [CrossRef]

10. Chow, C.L.; Jie, M. Forming limits of AL 6022 sheets with material damage consideration-Theory and experimental validation. Int. J. Mech. Sci. 2004, 46, 99-122. [CrossRef]

11. Luo, M.; Wierzbicki, T. Numerical failure analysis of a stretch-bending test on dual-phase steel sheets using a phenomenological fracture model. Int. J. Solids Struct. 2010, 47, 3084-3102. [CrossRef]

12. Hu, Q.; Li, X.F.; Han, X.H.; Chen, J. A new shear and tension based ductile fracture criterion: Modeling and validation. Eur. J. Mech. A-Solids 2017, 66, 370-386. [CrossRef]

13. Lou, Y.; Huh, H.; Yoon, J.W. Modeling of shear ductile fracture considering a changeable cut-off value for stress triaxiality. Int. J. Plast. 2014, 54, 56-80. [CrossRef]

14. Lou, Y.; Chen, L.; Clausmeyer, T.; Tekkaya, A.E.; Yoon, J.W. Modeling of ductile fracture from shear to balanced biaxial tension for sheet metals. Int. J. Solids Struct. 2017, 112, 169-184. [CrossRef]

15. Lou, Y.; Yoon, J.W. Anisotropic yield function based on stress invariants for BCC and FCC metals and its extension to ductile fracture criterion. Int. J. Plast. 2018, 101, 125-155. [CrossRef]

16. Mu, L.; Zang, Y.; Wang, Y.; Li, X.L.; Stemler, P.M.A. Phenomenological uncoupled ductile fracture model considering different void deformation modes for sheet metal forming. Int. J. Mech. Sci. 2018, 141, 408-423. [CrossRef]

17. Lou, Y.S.; Huh, H. Prediction of ductile fracture for advanced high strength steel with a new criterion: Experiments and simulation. J. Mater. Process. Technol. 2013, 213, 1284-1302. [CrossRef]

18. Lou, Y.S.; Zhang, S.J.; Yoon, J.W. Strength modeling of sheet metals from shear to plane strain tension. Int. J. Plast. 2020, 134, 102813. [CrossRef]

19. Zhao, C.C.; Yang, Z.Y.; Dong, G.J.; Wang, G.K. New development of ductile fracture criterion and its application on forming process of light alloy sheet. Trans. Nonferrous Met. Soc. China 2020, 30, 1791-1801.

20. Ko, Y.K.; Lee, J.S.; Huh, H.; Kim, H.K.; Park, S.H. Prediction of fracture in hub-hole expanding process using a new ductile fracture criterion. J. Mater. Process. Technol. 2007, 187, 358-362. [CrossRef] 
21. Brozzo, P.; Deluca, P.; Rendina, R. A new method for the prediction of formability in metal sheets. In Proceedings of the 7th Biennial Conference of the International Deep Drawing Research Group, Amsterdam, The Netherlands, 9-13 October 1972.

22. Oh, S.; Chen, C.C.; Kobayashi, S. Ductile Fracture in Axisymmetric Extrusion and Drawing-Part II: Workability in extrusion and drawing. J. Eng. Ind. 1979, 101, 36-44. [CrossRef]

23. Rice, J.R.; Tracey, D.M. On the ductile enlargement of voids in triaxial stress fields. J. Mech. Phys. Solids 1969, 17, $201-217$. [CrossRef]

24. Bao, Y.; Wierzbicki, T. A comparative study on various ductile crack formation criteria. Trans. ASME J. Eng. Mater. Technol. 2004, 126, 314-324. [CrossRef] 